\title{
Comparison Between Intravitreal Bevacizumab and Triamcinolone for Macular Edema Secondary to Branch Retinal Vein Occlusion
}

\author{
Jin Young Kim, MD, Sung Pyo Park, MD \\ Department of Ophthalmology, Kangdong Sacred Heart Hospital, Hallym University College of Medicine, Seoul, Korea
}

\begin{abstract}
Purpose: To compare the effects of intravitreal bevacizumab to those of triamcinolone acetonide injection for the treatment of macular edema secondary to branch retinal vein occlusion.

Methods: This retrospective study included 50 eyes of 50 patients who received a single injection of intravitreal bevacizumab $(1.25 \mathrm{mg} / 0.05 \mathrm{~mL}, 22$ eyes $)$ or triamcinolone acetonide $(4 \mathrm{mg} / 0.1 \mathrm{~mL}, 28$ eyes $)$ as the only treatment for macular edema secondary to branch retinal vein occlusion; all patients had a post-injection follow-up duration of $>24$ weeks. Best corrected visual acuity (BCVA), intraocular pressure (IOP), and central macular thickness (CMT) by optical coherence tomography were measured for up to 24 weeks after injection.

Results: BCVA was improved at 1, 4, 8,12 weeks post-injection in the bevacizumab group, and at 1, 4, 8 weeks post-injection in the triamcinolone group. No significant difference was found between the two groups except at 12 weeks. CMT decreased significantly within each group, and no significant difference between groups was found. In the bevacizumab group, no elevated IOP was observed, whereas IOP was significantly increased at 4,8 , and 12 weeks after triamcinolone injection; IOP was therefore significantly different between the two groups.

Conclusions: Intravitreal bevacizumab is a comparatively simple treatment method that can effectively improve BCVA and reduce CMT without ocular and systemic complications. Consequently, intravitreal bevacizumab injections may be useful as both an alternative and primary treatment for macular edema secondary to branch retinal vein occlusion.
\end{abstract}

Korean J Ophthalmol 2009;23:259-265 (c) 2009 by the Korean Ophthalmological Society.

Key Words: Bevacizumab, Branch retinal vein occlusion, Macular edema, Triamcinolone acetonide

Branch retinal vein occlusion (BRVO) is a common disease in which the retinal vein is compressed and occluded due to thickening of the arterial wall, primarily where the artery and vein cross. ${ }^{1}$ Retinal hemorrhage, vitreous hemorrhage, tractional retinal detachment, and macular edema due to BRVO lead to decreased visual acuity. Of these, macular edema is the most common cause of decreased visual acuity. ${ }^{2}$ Macular edema, characterized by high capillary pressure and abnormalities of the self-regulatory mechanism of the retinal bloodstream, is thought to occur due to leakage of body fluids and blood plasma components due to microaneurysms or damaged capillary endothelium because of the destruction of the normal blood and blood retinal barrier and pooling of these components at the outer plexiform, molecular layer, or inner nuclear layer.,

Several treatments to improve visual acuity and facilitate

Received: September 3, 2008 Accepted: October 29, 2009

Reprint requests to Sung Pyo Park, MD. Department of Ophthalmology, Kangdong Sacred Heart Hospital, Hallym University, \#445 Gil 1-dong, Gangdong-gu, Seoul 134-701, Korea. Tel: 82-2-2224-2274, Fax: 82-2-4702088, E-mail: sungpyo@hanafos.com anatomic recovery from macular edema due to retinal vein occlusion have been developed. These include grid pattern laser photocoagulation, vitrectomy, and intravitreal triamcinolone acetonide injection. The Branch Vein Occlusion Study (BVOS) reported that grid pattern laser photocoagulation improved visual acuity by up to $60 \%,{ }^{2}$ and many reports have shown that intravitreal triamcinolone acetonide injections are effective at improving visual acuity. ${ }^{5,6}$

However, intravitreal triamcinolone acetonide injections are also associated with complications such as the formation of cataracts and an increase in intraocular pressure. ${ }^{7,8}$ Furthermore, laser treatment of cases with media opacity, such as retinal hemorrhage, are challenging, and laser treatment is only effective for non-ischemi-type macular edema. ${ }^{9}$

Recently, it was reported that intravitreal anti-vascular endothelial growth factor (VEGF) antibody injections used to treat colon cancer had positive results on macular edema, ${ }^{10-12}$ and these injections have been used to treat various ocular diseases such as choroidal neovascularization. Rosenfeld et al. ${ }^{12}$ reported an improvement in visual acuity and a decrease in macular edema after intravitreal bevacizumab injection in patients with central retinal vein occlusion (CRVO). Similarly, Itturalde et al. ${ }^{11}$ reported an 
Table 1. Comparison of patient demographics and characteristics of intravitreal bevacizumab and triamcinolone acetonide injection group

\begin{tabular}{|c|c|c|c|}
\hline & $\begin{array}{c}\text { Bevacizumab } \\
\text { injection group }\end{array}$ & $\begin{array}{l}\text { Triamcinolone acetonide } \\
\text { injection group }\end{array}$ & $\begin{array}{l}p \text {-value between } \\
\text { injection groups }\end{array}$ \\
\hline$\overline{\text { Age (mean } \pm \mathrm{SD}, \text { range })}$ & $56.86 \pm 9.64(37-73)$ & $59.42 \pm 11.56(33-78)$ & $0.407^{*}$ \\
\hline \multicolumn{4}{|l|}{$\operatorname{Sex}(\%)$} \\
\hline Male & $10(45.5)$ & $11(39.3)$ & $0.621^{\dagger}$ \\
\hline Female & $12(54.5)$ & $17(60.7)$ & \\
\hline Pre injection BCVA $(\log M A R$, mean \pm SD) & $0.60 \pm 0.41$ & $0.67 \pm 0.28$ & $0.160^{*}$ \\
\hline Pre injection CMT $(\mu \mathrm{m}$, mean $\pm \mathrm{SD})$ & $399.64 \pm 128.32$ & $466.39 \pm 121.29$ & $0.057^{*}$ \\
\hline Pre injection IOP $(\mathrm{mmHg}$, mean $\pm \mathrm{SD})$ & $13.09 \pm 2.07$ & $13.36 \pm 2.57$ & $0.694^{*}$ \\
\hline $\begin{array}{l}\text { Mean time between injection and } \\
\text { diagnosis (wk, range) }\end{array}$ & $13.6(0-22)$ & $14.4(8-28)$ & \\
\hline \multicolumn{4}{|l|}{ Associated systemic disease (\%) } \\
\hline Hypertension & $14(63.6)$ & $16(57.1)$ & \\
\hline Diabetes mellitus & $5(22.7)$ & $7(25.0)$ & \\
\hline Hyperlipidemia & $2(9.0)$ & $3(10.7)$ & \\
\hline
\end{tabular}

$\mathrm{BCVA}=$ best corrected visual acuity; logMAR =logarithm of the minimal angle of resolution; $\mathrm{CMT}=$ center macular thickness; IOP=intraocular pressure.

Independent $t$-test; ${ }^{\dagger}$ Chi-square test.

anatomic decrease in macular edema and an improvement of visual acuity after injection of bevacizuamb in 16 eyes. Jaissle et al. ${ }^{10}$ reported similar results in BRVO patients. However, no study has compared intravitreal triamcinolone acetonide injection with intravitreal bevacizumab injection for macular edema secondary to BRVO. Thus, in this study, we compared the effects of intravitreal triamcinolone acetonide and bevacizumab injections to treat macular edema secondary to BRVO.

\section{Materials and Methods}

This retrospective study included 50 eyes of 50 patients who received a single injection of intravitreal bevacizumab $(1.25 \mathrm{mg} / 0.05 \mathrm{~mL}, 22$ eyes) or triamcinolone acetonide (4 $\mathrm{mg} / 0.1 \mathrm{~mL}, 28$ eyes) as the only treatment for macular edema from BRVO between October 2006 and December 2007. All patients had a post-injection follow- up time of $>24$ weeks.

Before treatment, best corrected visual acuity (BCVA), intraocular pressure (IOP), slit lamp examination, fundus examination, and central macular thickness (CMT) measurements based on optical coherence tomography were measured at baseline and at 1, 4, 8, 12, and 24 weeks after injection. Fluorescein angiography was also performed at baseline. BCVA was evaluated using a Snellen eye chart and converted into the visual acuity of log MAR (logarithm of the minimal angle of resolution) for statistical analyses. IOP was measured by Goldmann applanation tonometry and CMT was measured using a central macular thickness map (based on a center with a $0.5 \mathrm{~mm}$ radius) determined using optical coherence tomography (Stratus $\mathrm{OCT}^{\mathrm{TM}}$; Carl Zeiss Meditec Inc., Dublin, CA, USA). To determine underlying diseases, the medical history of all patients was taken, and blood pressure, blood coagulation, serum lipid levels, and blood sugar levels were evaluated.

We included macular edema cases that did not show foveal ischemia or subretinal, retinal, or vitreous hemorrhage upon fluorescein angiography and fundus photography with a visual acuity of under 20/40. If other media opacities were present that could account for the decrease in visual acuity such as corneal opacity, cataract, and vitreous hemorrhage, or if ischemic changeswere seen on fluorescein angiography, or if it was not clear whether the patient had ischemic type or non-ischemic type macular edema due to a severe retinal hemorrhage, the patient was excluded from the study. Patients who had previous treatment for macular edema or who had received treatments for other conditions such as laser treatment, intravitreal injection within 24 weeks were also excluded.

After instilling $0.5 \%$ proparacaine hydochloride topical eye drops 3 times every 5 minutes for topical anesthesia, the eye was irrigated with $5 \%$ povidone iodine, opened using a lid retractor, and then injected through the pars plana $3.0 \mathrm{~mm}$ posterior to the limbus in pseudophakic eyes and $3.5 \mathrm{~mm}$ posterior to the limbus in phakic eyes using a 30 gauge needle. To control intraocular pressure after the injection, anterior chamber paracentesis $(0.1 \mathrm{~mL})$ was performed. After the injection, an ophthalmic solution of the topical antimicrobial drug levofloxacin was administered 4 times per day for a week.

SPSS ver. 12.0.1 (SPSS Inc., Chicago, IL, USA) was used for statistical analyses and the chi-square test, paired $t$-test, Wilcoxon signed-rank test, and Mann-Whitney U test were used. Statistical significance was set at $p<0.05$.

\section{Results}

Twenty-two of 50 patients (22 of 50 eyes) received be- 
vacizumab injections. The male to female ratio in this patient group was $10: 12$, the mean age $( \pm \mathrm{SD})$ was $56.86 \pm 9.64$ years, with a range of 37 to 73 years. The mean period from the development of symptoms to the injection was 13.6 weeks (range, 0 to 22 weeks) (Table 1 ).

Prior to the administration of the drugs, there were no significant differences in initial BCVA, CMT, or IOP ( $p$ value $=0.160,0.057,0.694$, respectively) (Table 1$)$.

\section{Bevacizumab-injected group}

The mean BCVA $( \pm \mathrm{SD})$ before intravitreal bevacizumab injection was $\log \mathrm{MAR}+0.60 \pm 0.41$ and after $1,4,8,12$, and 24 weeks, it was $\operatorname{logMAR}+0.32 \pm 0.33,+0.27 \pm 0.34,+0.24 \pm$ $0.27,+0.24 \pm 0.26$, and $+0.50 \pm 0.29$, respectively. At $1,4,8$, and 12 weeks after the injections, there was a significant improvement from baseline within this group ( $p=0.001$ for 1 , 4,8 , and 12 weeks, respectively) (Fig. 1); however, no significant improvement was noted after 24 weeks $(p=0.064$ at 24 weeks). The intraocular pressure $( \pm \mathrm{SD})$ before the injection was $13.09 \pm 2.07 \mathrm{mmHg}$ and at $1,4,8,12$, and 24 weeks after the injection, the IOP in this group was 12.50 $\pm 2.63,12.23 \pm 2.72,12.55 \pm 2.09,12.0 \pm 2.78$, and $12.32 \pm 2.92$ $\mathrm{mmHg}$, respectively. Thus, during the follow-up period, there were no significant differences in IOP from baseline within the bevacizumab group $(p=0.298,0.67,0.52,0.52$, 0.162 at $1,4,8,12$, and 24 weeks) (Fig. 2). The thickness of macular edema based on the center macular thickness map generated by optical coherence tomography $( \pm \mathrm{SD})$ was $399.64 \pm 128.32 \mu \mathrm{m}$ before the injection, and $322.32 \pm 112.45$, $281.59 \pm 94.46,263.86 \pm 82.27,271.18 \pm 81.51$, and $297.32 \pm$ $86.56 \mu \mathrm{m}$ at weeks $1,4,8,12$, and 24 , respectively. This reduction in macular thickness was significant for all follow-up periods when compared to baseline ( $p=0.001$ for all postinjection periods vs. baseline) (Fig. 3).

\section{Triamcinolone-injected group}

Intravitreal triamcinolone acetonide injections were used to treat 28 patients ( 28 eyes). The male:female ratio in this group was $11: 17$. The mean age $( \pm \mathrm{SD})$ was $59.42 \pm 11.56$ years, with a range of 33 to 78 years, and the mean period from the development of symptoms to the injection was 14.4 weeks (range, 8 to 28 weeks). BCVA $( \pm \mathrm{SD})$ before the injection was $\log$ MAR $+0.67 \pm 0.28$, while the visual acuity after $1,4,8,12$, and 24 weeks was $\log$ MAR $+0.41 \pm 0.29$, $+0.32 \pm 0.30,+0.35 \pm 0.31,+0.55 \pm 0.32$, and $+0.64 \pm 0.31$, respectively; the improvements after 1,4 , and 8 weeks were statistically significant ( $p=0.001$ at 1,4 , and 8 weeks, $p=$ 0.070 at 12 weeks, $p=0.539$ at 24 weeks) (Fig. 1). In contrast to the bevacizumab group, however, IOP $( \pm \mathrm{SD})$ was $13.36 \pm 2.57 \mathrm{mmHg}$ before the injection and increased to $14.18 \pm 3.49,15.39 \pm 5.33,15.50 \pm 4.31,14.54 \pm 3.07$, and 13.50 $\pm 3.09 \mathrm{mmHg}$ after weeks $1,4,8,12$, and 24 , respectively. The differences from baseline at 4 and 8 weeks were significant ( $p=0.550,0.011,0.016,0.050,0.554$ for weeks 1 , $4,8,12$, and 24, respectively) (Fig. 2). The increase in IOP during the follow-up periods exceeded $21 \mathrm{mmHg}$ in 1 eye only, which indicates that although IOP increased 4 to 12 weeks after the injection, it could be controlled by medication. CMT $( \pm \mathrm{SD}$ ) was $466.39 \pm 121.29 \mu \mathrm{m}$ before the injection but decreased to $359.18 \pm 113.70,255.0 \pm 75.76,263.10 \pm 105.0$, $298.07 \pm 108.94$, and $356.68 \pm 106.06 \mu \mathrm{m} \mathrm{1,} \mathrm{4,} \mathrm{8,} \mathrm{12,} \mathrm{and} 24$ weeks after the injection, respectively; all these reduction in CMT in the triamcinolone group were significant $(p=0.001$ for all follow-up periods) (Fig. 3).

\section{Comparison of the Bevacizumab and Triamcinolone injection groups}

BCVA did not show a significant difference between the

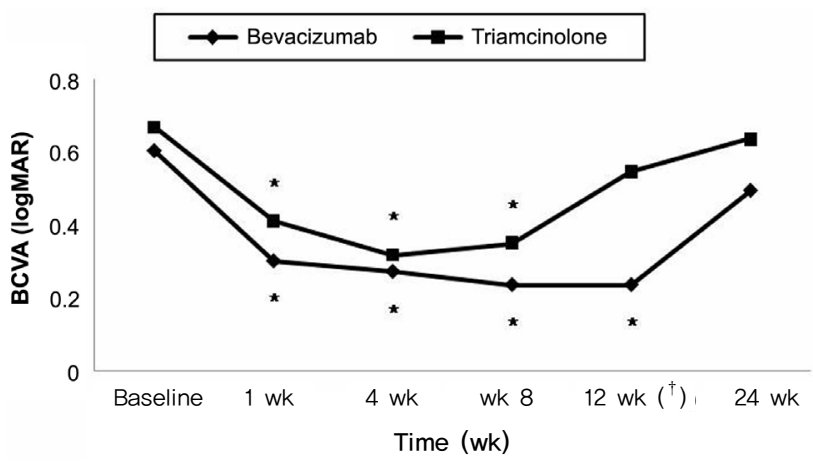

\begin{tabular}{ccccccc}
\hline & & Baseline & $1 \mathrm{wk}$ & $4 \mathrm{wk}$ & $8 \mathrm{wk}$ & $24 \mathrm{wk}$ \\
\hline BCVA & Bevacizumab & $0.6045 \pm 0.4135$ & $0.3182 \pm 0.3304$ & $0.2727 \pm 0.3369$ & $0.2364 \pm 0.2717$ & $0.2364 \pm 0.2592$ \\
& & & & & \\
& Triamcinolone & $0.6679 \pm 0.2842$ & $0.4107 \pm 0.2948$ & $0.3179 \pm 0.2995$ & $0.3500 \pm 0.3109$ & $0.5464 \pm 0.3249$ \\
\hline
\end{tabular}

$\mathrm{BCVA}=$ best corrected visual acuity; $\log \mathrm{MAR}=$ logarithm of the minimal angle of resolution.

Fig. 1. Comparison of the clinical course of best corrected visual acuity between the bevacizumab-injected eyes and triamcinolone acetonideinjected eyes in patients with macular edema secondary to branch retinal vein occlusion. The asterisk $(*)$ indicates a statistically significant changes $(p<0.05)$ from baseline within group, the dagger $(\dagger)$ means statistically significant difference $(p<0.05)$ between the bevacizumab and triamcinolone-injected eyes at each time point. 


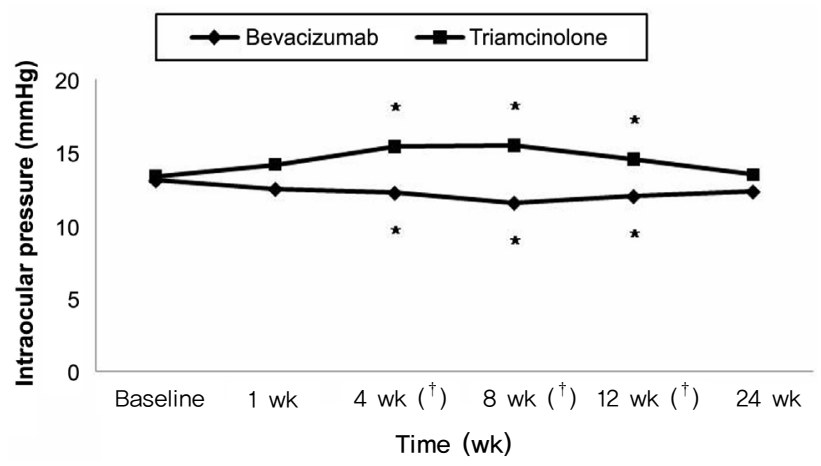

\begin{tabular}{|c|c|c|c|c|c|c|c|}
\hline & & Baseline & $1 \mathrm{wk}$ & $4 \mathrm{wk}$ & $8 \mathrm{wk}$ & $12 \mathrm{wk}$ & $24 \mathrm{wk}$ \\
\hline \multirow[t]{2}{*}{ IOP } & Bevacizumab & $13.0909 \pm 2.0681$ & $12.5000 \pm 2.6322$ & $12.2273 \pm 2.7243$ & $12.5455 \pm 2.0949$ & $12.000 \pm 2.7774$ & $12.3182 \pm 2.9177$ \\
\hline & Triamcinolone & $13.3571 \pm 2.5706$ & $14.1786 \pm 3.4859$ & $15.3929 \pm 5.3287$ & $15.5000 \pm 4.3076$ & $14.5357 \pm 3.0729$ & $13.5000 \pm 3.0852$ \\
\hline
\end{tabular}

$\mathrm{IOP}=$ intraocular pressure, $\mathrm{mmHg}$.

Fig. 2. Comparison of the clinical course of intraocular pressure between the bevacizumab-injected eyes and triamcinolone acetonide-injected eyes in patients with macular edema secondary to branch retinal vein occlusion. The asterisk $(*)$ indicates a statistically significant changes $(p$ $<0.05)$ from baseline within group, the dagger $(\dagger)$ means statistically significant difference $(p<0.05)$ between the bevacizumab and triamcinolone-injected eyes at each time point.

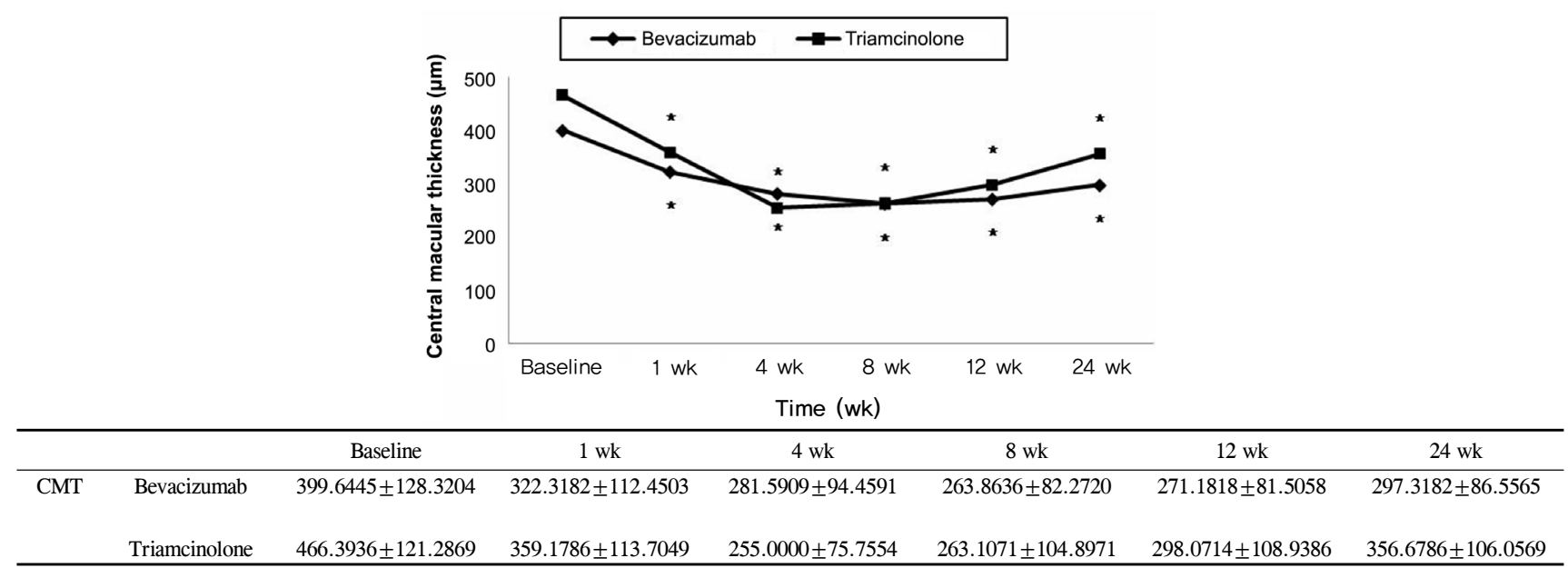

$\mathrm{CMT}=$ Central macular thickness, $\mu \mathrm{m}$.

Fig. 3. Comparison of the clinical course of central macular thickness between the bevacizumab-injected eyes and triamcinolone acetonide-injected eyes in patients with macular edema secondary to branch retinal vein occlusion. The asterisk $\left(^{*}\right)$ indicates a statistically significant changes $(p$ $<0.05)$ from baseline within group.

two groups during the follow-up period except for 12 weeks after the injections (Mann-Whitney $\mathrm{U}$ test, $p$-value $=0.132$, $0.317,0.135,0.000,0.124$ at $1,4,8,12$, and 24 weeks, respectively) (Fig. 1) and CMT was also not significantly different between the two groups throughout the follow-up period (Mann-Whitney U test, $p$-value $=0.207,0.309,0.860$, $0.401,0.062$ at $1,4,8,12$, and 24 weeks, respectively) (Fig. 3). However, the IOP at 4, 8, and 12 weeks after the operation was statistically and significantly higher in the intravitreal triamcinolone acetonide-injected group than the intravitreal bevacizumab-injected group (Mann-Whitney $\mathrm{U}$ test, $p$ value $=0.093,0.006,0.002,0.001,0.111$ at $1,4,8,12$, and 24 weeks, respectively) (Fig. 2).
No cataracts occurred during the follow-up period as complications after the injection. Furthermore, no general complications or other ocular complications such as iris neovascularization, neovascular glaucoma, retinal detachment, vitreal hemorrhage, or endophthalmitis were observed.

\section{Case reports}

Case 1. A 73-year-old female patient was referred to our hospital by the local clinic with a 2 -week history of reduced visual acuity in the right eye. The medical history of the patient revealed that she had been diagnosed with hypertension 10 years previously and was currently been 

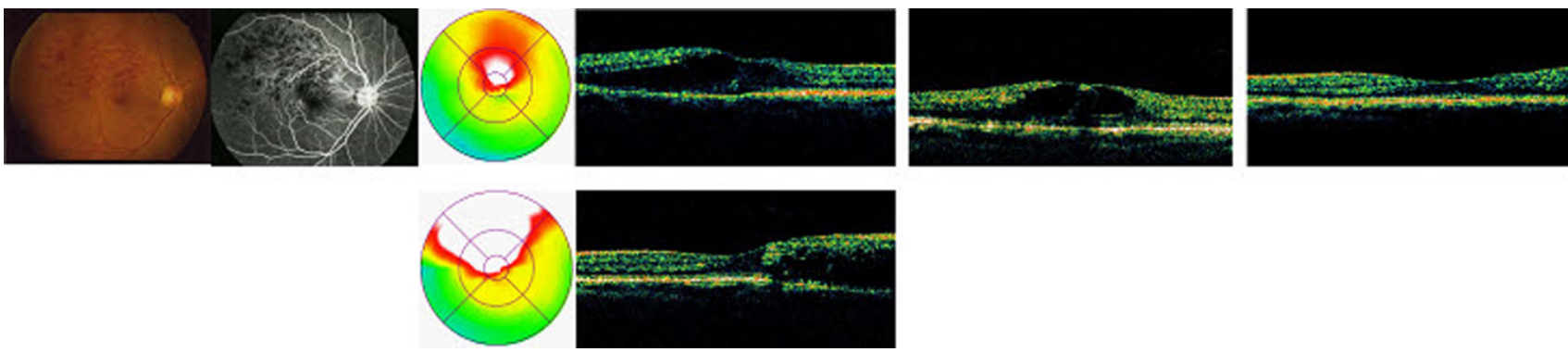

Fig. 4. Color fundus photograph, flourescein angiograph, optical coherence tomography at baseline, 4 wk, 12 wk (top row), 24 wk (bottom row) of case 1 after intravitreal injection of triamcinolone acetonide for macular edema in vein occlusion.
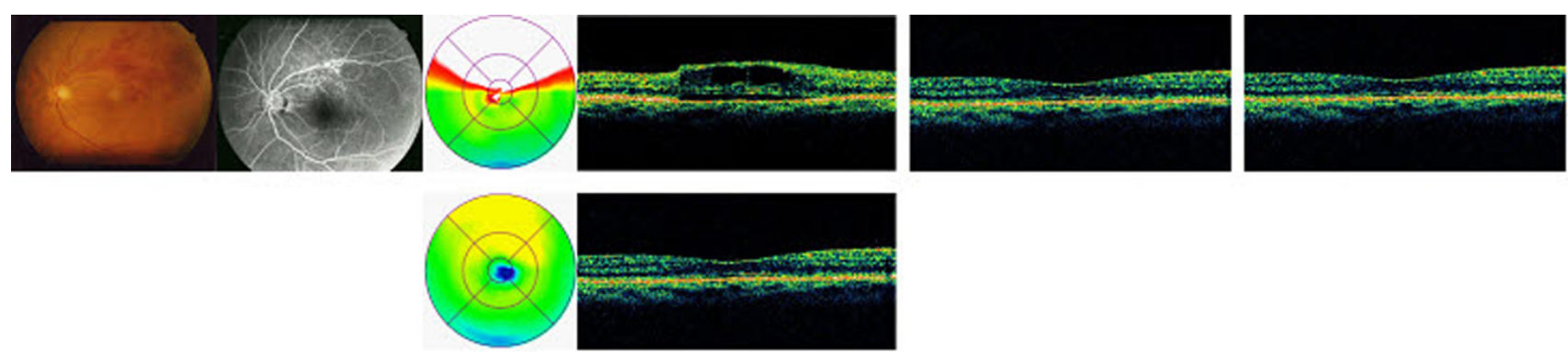

Fig. 5. Color fundus photograph, flourescein angiograph, optical coherence tomography at baseline, 4 wk, 12 wk (top row), 24 wk (bottom row) of case 2 after intravitreal injection of Bevacizumab for macular edema in vein occlusion.

treated for this. When she was referred to our hospital, her BCVA was 20/100. A flame-shaped retinal hemorrhage caused by branch retinal vein occlusion was seen upon fundus examination, and was accompanied by severe macular edema. No hyperfluorescence due to neovascularization or ischemic changes were observed upon fluorescein angiography. One week after intravitreal triamcinolone acetonide injection was performed, her visual acuity had improved and optical coherence tomography revealed a decrease in macular edema for up to 12 weeks, but macular edema recurred after 24 weeks, as did a decrease in the patient's visual acuity (Fig. 4).

Case 2. A 37-year-old female patient visited our hospital due to a dimming of vision in her left eye and a severe decrease in visual acuity 5 weeks prior. The patient had been diagnosed with hypertension 2 years previously and was currently taking oral medication for hypertension. The BCVA of the patient at the time of examination was 20/63. Fundus examination revealed a flame-shaped retinal hemorrhage and macular edema. Fluorescein angiography did not show hypofluorescence due to retinal hemorrhage. An intravitreal bevacizumab injection was administered, and the visual acuity of the patient improved from one week after the injection till 12 weeks; similarly, macular thickness decreased for up to 24 weeks (Fig. 5).

\section{Discussion}

Grid pattern laser photocoagulation and intravitreal triamcinolone acetonide injections for BRVO improve visual acuity and decrease macular edema, ${ }^{2,13}$ but these treatments have several limitations. Grid pattern laser photocoagulation is only effective for non-ischemic type BRVO and several treatment episodes are required. ${ }^{14}$ Furthermore, if macular hemorrhage is present, it is difficult to treat immediately. If severe macular ischemia is present, treatment is ineffective. ${ }^{15}$ Intravitreal triamcinolone acetonide injections increase IOP, the formation of cataracts, and the occurrence of endophthalmitis; furthermore, the long-term effectiveness of this treatment is also unclear. ${ }^{8}$

VEGF is a core mediator of intraocular neovascularization and macular edema, and animal experiments have shown that this molecule can promote ischemia caused by retinal vein occlusion. Furthermore, inhibition of VEGF is used to treat various conditions. ${ }^{16-18}$

In this study, we compared the effects of intravitreal triamcinolone acetonide injections and bevacizumab injections. With regard to BCVA, although the bevacizumab group showed a significant improvement in visual acuity for up to 12 weeks compared to baseline, while the triamcinolone group showed an improvement up to 8 weeks post-injection, the visual acuity after these time periods decreased in both groups and was not significantly different from the baseline values, consistent with existing studies.

Rabena et al. ${ }^{19}$ reported that macular edema accompanied by BRVO recurred after 2.1 months after intravitreal bevacizumab injection, while $\mathrm{Wu}$ et al. ${ }^{20}$ and Badala ${ }^{21}$ reported that the effects of intravitreal bevacizumab injection treatment for macular edema due to CRVO and BRVO disappeared after 6 weeks. Macular edema has also been reported to recur after intravitreal triamcinolone acetonide injection, although Krepler et al. ${ }^{22}$ reported that improvements in macular edema 
and visual acuity in macular edema patients secondary to CRVO were observed for up to 3 months after intravitreal triamcinolone acetonide injection.

We investigated improvements in visual acuity for a longer period than existing studies, and examined BRVO patients and patients without changes in ischemia and neovascularization, which may explain the differences between our findings and those reported in previous studies. Choi et al. ${ }^{23}$ reported that patients with macular edema secondary to non-ischemic BRVO showed significant differences in macular edema thickness for up to 6 months after bevacizumab injection. Similarly, in our study, the thickness of macular edema after injection of either bevacizumab or triamcinolone acetonide decreased significantly throughout the follow-up period. However, although visual acuity improved significantly for up to 12 weeks and 8 weeks for bevacizumab or triamcinolone acetonide injections, respectively, after these time periods, it did not improve. These results indicate that injection of bevacizumab or triamcinolone acetonide decreases macular edema by reducing the thickness of macular edema, but several other factors also appeared to be involved in determining visual acuity. The visual acuity of BRVO patient is known to depend on how much blood circulation remains and the regeneration of blood circulation. ${ }^{24,25}$ The foveal capillary plexus network contains the veins closest to the fovea; differences in the state of this capillary plexus network have been postulated to result in different visual outcomes in different cases. Clemett et al. ${ }^{26}$ and Schilling and Jones ${ }^{27}$ reported that if the capillary plexus network is destroyed, visual outcomes are worse, while Kang et al. ${ }^{28}$ reported the if the range of macular ischemia is small and the perifoveal capillary network is intact, the final visual acuity is better.

The IOP after intravitreal triamcinolone acetonide injection increased significantly after 4,8 , and 12 weeks, but decreased to baseline after 24 weeks. The IOP exceeded 21 $\mathrm{mmHg}$ in only one case, but was controlled by medication. In contrast, no increase in IOP was seen after bevacizumab injection and no systemic complications such as myocardial infarction and cerebral infarction were observed.

Accordingly, intravitreal bevacizumab injections resulted in a temporary improvement in the visual acuity of macular edema patients secondary to BRVO and reduced macular thickness. Thus, intravitreal bevacizumab iassociated with fewer ocular complications than intravitreal triamcinolone acetonide injections, which is important when repeated injections are required.

Thus, we conclude that intravitreal bevacizumab may be a better treatment option for macular edema secondary to BRVO than intravitreal triamcinolone acetonide injections. However, due to analysis of a limited number of patients, the absence of a control group, the limitations associated with a retrospective study, and the lack of inclusion of an ischemic BRVO group, more cases as well as control patients need to be evaluated to conclusively demonstrate the advantages of intravitreal bevacizumab injections versus intravitreal triamcinolone acetonide injections for the treatment of macular edema secondary to BRVO.

\section{References}

1. Weinberg D, Dodwell DG, Fern SA. Anatomy of arteriovenous crossing in branch retinal vein occlusion. Am J Ophthalmol 1990; 109:298-302.

2. The Branch Vein Occlusion Study Group. Argon laser photocoagulation for macular edema in branch vein occlusion. Am JOphthalmol 1984;98:271-82.

3. Hayreh SS. Classification of central retinal vein occlusion. Ophthalmology 1983;90:458-74.

4. Wallow IH, Danis RP, Bindley C, Neider M. Cystoid degeneration in experimental branch vein occlusion. Ophthalmology 1988;95: 1371-9.

5. Cheng $\mathrm{KC}, \mathrm{Wu} \mathrm{WC}$. Intravitreal triamcinolone acetonide for patients with macular edema due to branch retinal vein occlusion. Kaohsiung J Med Sci 2006;22:321-30.

6. Cakir M, Dogan M, Bayraktar Z, et al. Efficacy of intravitreal triamcinolone for the treatment of macular edema secondary to branch retinal vein occlusion in eyes with or without grid laser photocoagulation. Retina 2008;28:465-72.

7. Nauck M, Karakiulakis G, Perruchoud AP, et al. Corticosteroids inhibit the expression of the vascular endothelial growth factor gene in human vascular smooth muscle cells. Eur J Pharmacol 1998;341:309-15.

8. Cekic O, Chang S, Tseng JJ, et al. Intravitreal triamcinolone injection for treatment of macular edema secondary to branch retinal vein occlusion. Retina 2005;25:851-5.

9. Battaglia Parodi M, Saviano S, Ravalico G. Grid laser treatment in macular branch retinal vein occlusion. Graefes Arch Clin Exp Ophthalmol 1999;237:1024-7.

10. Jaissle GB, Ziemssen F, Petermeier K, et al. Bevacizumab for treatment of macular edema secondary to retinal vein occlusion. Ophthalmology 2006;103:471-5.

11. Iturralde D, Spide RF, Meyerle CB, et al. Intravitreal bevzcizumab (avastin) treatment of macular edema in central retinal vein occlusion: a short term study. Retina 2006;26:279-84.

12. Rosenfeld PJ, Fung AE, Puliafito CA. Optical coherence tomography findings after an intravitreal injection of bevacizumab (avastin) for macular edema from central retinal vein occlusion. Ophthalmic Surg Lasers Imaging 2005;36:336-9.

13. Lang GE, Handel A. Results of laser coagulations of branch retinal vein occlusions. Klin Monatsbl Augenheilkd 1993;203:180-8.

14. Estrick E, Subramanian ML, Heier JS, et al. Multiple laser treatments for macular edema attributable to branch retinal vein occlusion. Am J Ophthalmol 2005;139:653-7.

15. Hayreh SS, Rubenstein L, Podhajsky P. Argon laser scatter photocoagulation in treatment of branch retinal vein occlusion: a prospective trial. Ophthalmologica 1993;206:1-14.

16. Aiello LP, Bursell SE, Clermont A, et al. Vascular endothelial growth factor-induced retinal permeability is mediated by protein kinase $\mathrm{C}$ in vivo and suppressed by an orally effective beta-isoform-selective inhibitor. Diabetes 1997;46:1473-80.

17. Vinores SA, Youssri AI, Luna JD, et al. Upregulation of vascular endothelial growth factor in ischemic and non-ischemic human and experimental retinal disease. Histol Histopathol 1997;12:99109.

18. Antonetti DA, Barber AJ, Hollinger LA, et al. Vascular endothelial growth factor induces rapid phosphrylation of tight junction proteins occluding and zonula occluden 1: a potential mechanism for vascular permeability in diabetic retinopathy and tumors. $J$ 
Biol Chem 1999;274: 23463-7.

19. Rabena MD, Pieramici DJ, Castellarin AA, et al. Intravitreal Bevacizumab (Avastin) in the treatment of macular edema secondary to branch retinal vein occlusion. Retina 2007;27:419-25.

20. Wu L, Arevalo JF, Roca JA, et al. Comparison of two doses of intravitreal bevacizumab for treatment of macular edema secondary to branch retinal vein occlusion. Retina 2008;28:212-9.

21. Badalà $F$. The treatment of branch retinal vein occlusion with bevacizumab. Curr Opin Ophthalmol 2008;19:234-8.

22. Krepler K, Ergun E, Sacu S, et al. Intravitreal triamcinolone acetonide in patients with macular edema due to central retinal vein occlusion. Acta Ophthalmol Scand 2005;83:71-5.

23. Choi CU, Seo SW, Yang YS. Different effect of IVTA in the management of macular edema secondary to perfusion and ischemic type BRVO. J Korean Ophthalmol Soc 2007;48:49-54.
24. Green WR, Chan CC, Hutchins GM, Terry JM. Central retinal vein occlusion: a prospective histopathologic study of 29 eyes in 28 cases. Retina 1981;1:27-55.

25. Glacet-Bernard A, Coscas G, Chabanel A, et al. Prognostic factors for retinal vein occlusion: prospectivge study of 175 cases. Ophthalmology 1996;103:551-60.

26. Clemett RS, Kohner EM, Hamilton AM. The visual prognosis in retinal branch vein occlusion. Trans Ophthamol Soc UK 1973;93: 523-35.

27. Shilling JS, Jones CA. Retinal branch vein occlusion: a study of argon laser photocoagulation in the treatment of macular edema. Br J Ophthalmol 1984;68;196-8.

28. Kang SJ, Chin HS, Moon YS. Visual prognosis of macular edema associated with macular ischemia in branch retinal vein occlusion. J Korean Ophthalmol Soc 2002;43:1621-8. 